\title{
Global Academic Journal of Humanities and Social Sciences
}

\section{Socio-Cultural Variables as Correlates of Youths' Vulnerability to Suicide in Ekiti State, Nigeria}

\author{
*Corresponding Author: \\ Abdu-Raheem Bilqees \\ Olayinka (Ph.D.) \\ Article History \\ Received: 05.06.2021 \\ Accepted: 02.07.2021 \\ Published: 17.07.2021
}

Abdu-Raheem Bilqees Olayinka (Ph.D.) ${ }^{1 *}$, Alonge, Rufus Ajayi (Ph.D.) ${ }^{1}$

1Department of Social Science Education, Faculty of Education, Ekiti State University, Ado-Ekiti, Nigeria

Abstract: This study investigated socio-cultural variables as correlate of youths' vulnerability to suicide in Ekiti state, Nigeria. Specifically, the study considered the relationships of gender, religious affiliation and educational attainment with youth vulnerability to suicide. Descriptive research design of the exploratory type was adopted for the study. The population comprised of both male and female youth in Ekiti state while the sample consisted of 300 youths selected through stratified random sampling technique. The instrument for the study was a questionnaire designed by the researchers. The validity of the instrument was done through face and content validity procedures while Cronbach alpha was used for the reliability. The reliability coefficient of 0.79 was obtained. Three research hypotheses were generated and tested at 0.05 level of significance. The data collected were analysed using Frequency count, Mean, Standard Deviation and Pearson Product Moment Correlation statistical tools. The study found that there is relationship between gender, religious affiliation, educational attainment and youth vulnerability to suicide in Ekiti state. It was therefore recommended that parents should make provisions for their children without gender discrepancy. Parents should also give sound education to their children, religious leaders should preach against suicide and government should provide functional education and jobs for youths.

Keywords: Youth, Socio-cultural variables, Suicide, Vulnerability, Personality disorder.

Copyright (C) 2021 The Author(s): This is an open-access article distributed under the terms of the Creative Commons Attribution 4.0 International License (CC BY-NC 4.0) which permits unrestricted use, distribution, and reproduction in any medium for non-commercial use provided the original author and source are credited.

\section{INTRODUCTION}

It is very disheartening to receive the bad news of a youth with promising future just passing away through suicide. The act can be very devastating and may be one of the worst tragedies to befall a fellow family member and acquaintance or friends. Suicide is derived from the Latin word Suicecdare (meaning, to kill oneself). Suicide ideation according to Oginyi, Mbam, Sampson, Chukwudi and Nwoba (2018) is a major psychological killer of humans. It has been defined by the World Health Organization as "the act of killing oneself, deliberately initiated and performed by the person concerned in the full knowledge or expectation of its fatal outcome (Uchendu, Ijomone and Nwanchukwu 2019). Nnorom (2019) posited that suicide is the accumulation of processes and actions leading to the extermination of one's life by him or herself.

According to WHO (2009) suicide is an act deliberately initiated and performed by a person in the full knowledge of its fatal outcome. WHO (2012) asserted that more than one million people lose their lives through suicide every year. WHO (2013) posited that millions of people died yearly as a result of high prevalence of suicide and very worrisome because it occurs mostly among young adolescents. WHO (2015) noted that suicide occurs throughout life span and it is the second leading cause of death among 15-35 years old. Early adolescents to young adulthood witness the biggest increase in number of 
suicide deaths throughout lifespan (WHO 2017). Suicide is the second leading causes of death for adolescents worldwide (WHO 2017). An average of 100,000 youths commit suicide each year making youth suicidal behaviour a serious social problem in Nigeria and many countries of the world (WHO, 2018).

The incidence of attempted suicide is 20 times as common as completed suicide. It has further been predicted that in year 2020, 153 million people will die of suicide representing one in each every 20 deaths (WHO, 2001, Bertoloto and Fleichman 2002). WHO further estimated that for the year 2015, approximately 1.5 million of human will die from suicide and 20 to 30 times larger people will commit suicide. Animashaun and Animashaun (2016) opined that there are two major suicidal behaviours that are common to all suicidal cases, namely non- fatal and fatal suicidal behaviour. It was stated that fatal suicidal behaviour refers to completed suicidal behaviour which reflects the person intent to die and where the victim has managed to achieve the determined goal. In contrary to this, non- fatal suicidal behaviour refers to suicidal behaviour that does not in any way end the person's life, instead embodies several manifestations such as those seen in attempted murder.

According to Oginyi, Mba, Sampson, Chukwudi and Nwoba (2018) suicidal behaviour may be exhibited by individuals as a result of health, psychological, social and cultural problems including mental disorder, depression, loss of loved ones, loss of jobs, academic failure and family disorder. Some of the noted cases of suicide as applicable in Nigeria range from hanging, consumption of pesticides poisons to the usage of firearms which is not too common. WHO estimates that about 788,000 individuals died of suicide in 2015 and approximately $79 \%$ of all suicide death occurred in Low and Medium Income Countries (LMICs) in 2016. The Daily Times (2018) identified 13 causes of suicide in Nigeria among which are mental illness, unemployment, depression, financial problem, stress, and social isolation, alcohol abuse, smoking, natural disaster such as flooding, mental derangement, physical health deterioration, loss of job and strained relationship.

The issue of suicide is not peculiar to Nigeria and it is not true fact that Nigeria has the highest suicide rate in Africa (WHO 2016). WHO (2018) noted that people of all ages commit suicide which is a tragedy that have great adverse effects on the families, community and the nation in general. Publications of WHO recently also suggested that Nigeria has one of the highest rates of suicide in the world with estimation of 15 per 100,000 population (WHO 2019). However, the data as shown below revealed that Nigeria had an age - standardized suicide rate of $17.3 \%$ per 100,000 people in 2016 which placed $7^{\text {th }}$ on the continent and Lesotho has the highest suicide rate in this score, at 28.9 suicide rate per 100,000 people and Morocco has the lowest.

Table-1: Suicide Rates in Some African Countries

\begin{tabular}{|l|l|l|l|}
\hline \multicolumn{3}{|l|}{ Highest Countries } & Lowest Countries \\
\hline & Rate \% & & Rate \% \\
\hline Lesotho & 28.9 & Morocco & 3.1 \\
\hline Cote d'Ivoire & 23 & Sao Tome and Principe & 3.1 \\
\hline Equatorial Guinea & 22 & Tunisia & 3.2 \\
\hline Cameroon & 19.5 & Algeria & 3.3 \\
\hline Uganda & 20 & Egypt & 4.4 \\
\hline Zimbabwe & 19.1 & Libya & 5.5 \\
\hline Nigeria & 17.3 & Kenya & 5.6 \\
\hline Eswatim & 16.7 & South Sudan & 6.1 \\
\hline Togo & 16.6 & Madagascar & 6.9 \\
\hline Sierra Leone & 16.1 & Manrihus & 7.3 \\
\hline Benin & 15.7 & Guinea Bisau & 7.4 \\
\hline Chord & 15.5 & Mauritania & 7.5 \\
\hline
\end{tabular}

Source: Age-standardized, WHO, 2016.

Youths are young people between the ages of thirteen and thirty-five years; among these are teenagers and young adults who may still be carrying over some of the characteristics of adolescence. They are vibrant, energetic, inquisitive, adventurous, risk takers and identity seekers (Nduka-Ozo, 2016). Average Nigeria youths are youngsters who have grown up under the threat of having no future as a result of depression and frustration that becloud the visions, dreams and aspirations. However, youths who find themselves in difficult physical, social, economic, psychological and cultural situations may decide to take their own lives through suicide. Eneh (2017) noted that the problem 
of suicide was worsening as a result of economic hardship in Nigeria which makes the youth to face financial difficulties, health challenges and unemployment. Oginyi, Mbam, Sampson, Chukwudi and Nwoba (2018) posited that suicide has become the most worrisome psychological problem that significantly lead to death among university undergraduates in Nigeria.

Suicide as a social problem is most critical among youths whereby many of them die from suicide than from cancer, heart diseases, Aids or stroke (WHO 2016, Animashaun and Animashaun 2016). Recently, there has been a new perceptive towards suicide, in fact, there has been a pyramid shift from what it is used to be. The Yoruba in Southwest Nigeria has a general parlance that supported the incidence of suicide with a saying that "Iku ya Jesin" meaning that death is better or preferred to ignominy. This was common to the elderly in the past, but what could bring such idea to a vibrant youth? The scope of suicide in Nigeria is hidden under incomplete suspicion and sociocultural issues surrounding the menace and its related stigma (Okoedion and Okolie 2019).

A good number of causes have been put forward as the likely causes of suicide among youth. Falana, Onijigin \& Alao (2017), categorized causes of suicide into three- Psychological view, Socio-Cultural view and Biological view. The researchers are interested in the socio-cultural view of the causes of suicide among the youth. Falana et al. (2017) posited that the vulnerability to suicide among the youth is a function of how attached a person is to social groups as the family, religious affiliations and community. It was affirmed that the more a person belongs to social groups, the lower the vulnerability of such individual to suicide. The implication of this is that people who have poor relationship with society are at greater risk of killing themselves because many of them entered into depression that intensify their vulnerability to suicide.

Varieties of causes notwithstanding, the researchers looked at the relationships between youth suicide vulnerability and religious affiliations, gender and educational attainment. Each of these factors will be discussed briefly as related to youth suicide. The rate at which youth of this generation commit suicide is a great concern to all stakeholders and this represents a serious social problem in many countries. Globally, at least 100, 000 youths commit suicide each year (WHO 2008). Specifically United State of America (U.S.A) accounts for $12 \%$ of all death reported for youth suicide annually.

\section{Factors Contributing to Youth Vulnerability to Suicide in Ekiti State}

\section{Gender and Youth Vulnerability to Suicide}

Gender as a factor seems to have generated a lot of controversies available depicts that the rate of suicide among male is about 25.3 per 100,000 and for female 6.5 per 100,000 (NIMSS, 2002, Animashaun \& Animashaun, 2016). However, the suicide incidence amongst men is on the increase than women. This could be as a result of the economic recession and degradation. What could be responsible for high rate of suicide among males than females? The answer to this could be ego on the part of the men fold. Ego seems not to allow men seek for help because they see it as a failure on their part as they believed that conventional men are supposed to be in control at all times. Adewuya and Oladapo (2019) found that lack of maternal care is significant to suicidal behaviour of female and male adolescents. They discovered that male adolescents without mother care also display suicidal behaviour but not as much as those of female counterparts.

In addition, Powell, (2013) asserted that in England and Wales, the number of male suicides over age of 15 from 2001 to 2011 totaled 38, 621 and against women in the same period totaled 12,780. The difference was 25,841. Falana et al (2017) observed that men differ greatly from women in their vulnerability to suicide. It was stated that 19 of every 100,000 men commit suicide each year as against the suicide rate for women which is 4 of every 100,000 (Falana et al, 2017).In addition, Uchendu, Ijomone and Nwachoko (2019) discovered that suicide is a relatively rare problem affecting mainly young males. While considering the males to females ratio to suicide victims is $3.2-1$ which indicates male predominance. Studies cited in Uchendu et al. (2019) emphasized the predominance of male over female. However, the ratio of male to female in the following in places Nigeria are 7-1, 4.3-1, and 3.6-1 in PortHarcourt/Aba, Benin-City and Ile-Ife respectively. It was further stressed by the researchers that many nations of the world, male suicide behaviour predominate except in China with high rates of females than male especially among the rural women.

WHO (2008) discovery that gender does have influence on suicidal behaviours and that attempted suicide was most common among females with the age bracket of 15-24 years old than their male counterparts. WHO (2018) observed that suicide accounts for 50 percent of all violent deaths in men and 71 percent in women. However, Eze, Chukwuorji, Zacchaeus, Lorfa and Nwonyi (2019) found significant relationship between gender and 
suicidal ideation. They found that girls were higher in suicidal ideation than boys. Nyundo, Manu, Regan, Ismail, Chukwu, Dessie, Njau, Kaaya \& Fawzi (2020) posited that female adolescents were at higher risk of depression and they display higher rates of suicidal tendencies and suicide attempts. Generally, suicide is a gender issue that can no longer be ignored or glossed over especially as it affects the youths.

\section{Religious Affiliation and Youth Vulnerability to Suicide}

There is a general assumption that involvement in many world religions reduces suicide incidence especially for religions that teach eternal damnation for those who commit suicide and considered it as a sin. This in most cases may help account for the differences based on religious affiliation and belief system. In Nigeria, the three major religions, Islam, Christianity and Traditional emphasized that killing oneself is an abomination and punishable by the Supreme Being. The three major religions preach life after death (Offiah and Obiorah 2014). It was observed that suicide incidence is likely to be reduced by religious involvement and participation in religious activities and other programmes rather than being a member of a religious organization or simply by affiliation. Again, Uchendu, Ijomone and Nwachoko (2019) posited that societies that are highly religious are generally known to have low suicide rate.

Countries that are mostly Catholic, Jewish Muslims appears to have low suicide cases. In these countries, strict prohibitions against suicide or strong religious tradition and doctrine prevent majority of followers from committing suicide but this is not so in Austria. Despite the fact that it is predominantly Roman Catholic country, it has one of the highest rates in the world (Falana et al., 2017). This is contrary to the role believed to be played by religion in reducing vulnerability to suicide among adherents. Some religious organizations/sects portray suicide as a legitimate behaviour in certain circumstances; some religious sects/groups promote suicide as a means of martyrdom in a war against enemy. A good example of this is the incidence of suicides bombers in Nigeria among the Boko-Haram syndicates which can be found in the following websites: (www.cfr.org, www.voanews.com, www.nytimes.com, www.bbc.com, www.hrw.org, www.france24.com, www.tandfonline.com).

\section{Educational Attainment and Youth Vulnerability to Suicide}

Educational attainment is another major factor that further contributed to youth suicide in the society. Education could determine a decrease or an increase in the incidence of youth suicide. Philips and Hempstead (2017), opined that educational attainment (highest grade of school completed in college and above) is negatively associated with the suicide rate and a $1 \%$ increase in school completed would reduce suicide by $0.19 \%$. Such result indicates more educated individuals are less likely to commit suicide due to higher level of satisfaction in life.

Arising from a research carried out by Abel and Kruger (2005), it was found that people with low educational attainment is associated with a higher risk of suicide as well as all-cause death. It was further revealed that high educational attainment is associated with a better overall health and a lower mortality.

The base line here is that the correlation between suicide rates and educational attainment with household income were both negative and statistically significant. Meaning that, poverty was not significantly related to suicide incidence. It was noted by Abel and Kruger (2005), that higher education and income were associated with a decrease in suicide incidence in 2001. However, Kim, Kim, Choi, Lee and Park (2016) found that low education and unemployment of young adult are highly related to suicidal attempt in Ebonyi State University. Adewuya and Oladele (2019) posited that academic difficulties were significantly associated with adolescent suicidal behaviour in Lagos state of Nigeria.

\section{Statement of the Problem}

Several factors like psychological, economic, social, environmental, physical, cultural and family history have been considered as part of factors associated with significant increase in the incidence or occurrence of youth suicide cases. The researchers observed that good numbers of youth are frustrated, depressed, emotionally and psychologically imbalance, may be as a result of economic downturn, physical and mental health issues, family disruption, physical abuse, unemployment/ loss of jobs or disappointment from opposite gender as casual friends or fiancés. It was also noted that parents, foster parents, schools, community, government and other stakeholders appear not to be aware that today's youths need more attention and supports for easy transformation from youth to adulthood as a result of various challenges facing them. It was also observed that the stakeholders were not conscious of the fact that just as depression, stress, anxieties and disappointments affect the elderly, so it does to the youth also. However, other factors that could influence youth vulnerability to suicide such as gender, religious affiliation and educational 
attainment were considered in this study. The researchers are interested in finding whether or not there is relationship between gender, religious affiliation, educational attainment and youth vulnerability to suicide in Ekiti State, Nigeria.

\section{Research Hypotheses}

In an attempt to proffer solution to the problems raised, the following research hypotheses were generated and tested in this study;

1. There is no significant relationship between gender and youth vulnerability to suicide in Ekiti State.

2. There is no significant relationship between religious affiliation and youth vulnerability to suicide in Ekiti State.

3. There is no significant relationship between educational attainment and youth vulnerability to suicide in Ekiti State.

\section{METHODOLOGY}

The research design used for this study was the descriptive research design of the exploratory type whereby large copies of questionnaire were given out to the respondents who are youth within the age of 13- 35 years. This is done to be able to sieve out those who are not within the age brackets and it provides the researchers the opportunity to utilize quantitative approach in collecting and analyzing data collected for the purpose of the study. The population comprised of all youth both female and male in Ekiti State, Nigeria. The sample consisted of 300 youths selected through stratified random sampling technique to accommodate the gender and religious affiliation strata from two senatorial districts (Central and South) out of the three senatorial districts in Ekiti State.

Fifty youths were selected from each of the three Local Government Areas in each senatorial district making a total of six Local Government Areas and two senatorial districts arriving at 300 youths altogether. The instrument used to collect the data was a questionnaire and validity was done through face and content validity procedure. The reliability was done using Cronbach alpha. The instrument which was administered on 20 youths outside the six Local Government areas used for the study yielded the reliability coefficient of 0.79 which is adequate enough for the study. The questionnaire was divided into two sections. Section A was designed to get information on youths' bio-data and section B was designed to assess the level of vulnerability of the youth to suicide. The instrument was personally administered by the researchers and six research assistants at various Local Government areas. This was aimed at obtaining uniform instruction on the questionnaire. Data collected for the study were analysed using Frequency count, Mean, Standard Deviation and Pearson Product Moment Correlation. All the hypotheses were tested at 0.05 level of significance.

\section{RESULTS AND DISCUSSION \\ Results \\ Research hypothesis 1}

There is no significant relationship between gender and youth vulnerability to suicide.

Table-2: Pearson Correlation of Gender and Youth Vulnerability to Suicide

\begin{tabular}{|l|c|c|c|c|c|c|l|}
\hline Variable & N & Mean & S.D. & Df & r-cal & r- tab & Remark \\
\hline Gender & 300 & 52.94 & 8.98 & & & & \\
\cline { 1 - 5 } Youth Vulnerability to Suicide & 300 & 14.48 & 2.34 & 298 & $76.490^{*}$ & 1.980 & Sig. \\
\hline
\end{tabular}

Table 2 above shows that gender recorded mean score of 52.94 and standard deviation of 8.98 while youth vulnerability to suicide obtained a mean score of 14.48 and standard deviation of 2.34 (the $r$ 76.49; $\mathrm{P}<0.05$ ). Therefore, the null hypothesis is rejected. This implies that, there is a significant relationship between gender and youth vulnerability to suicide.

\section{Research hypothesis 2}

There is no significant relationship between religious affiliation and youth vulnerability to suicide.

In order to test this hypothesis, scores on religious affiliation and youth vulnerability to suicide were computed and subjected to Pearson Product Moment Correlation at 0.05 level of significance. The result is presented in table 3:

Table-3: Pearson Correlation of Religious Affiliation and Youth Vulnerability to Suicide

\begin{tabular}{|l|l|l|l|l|l|l|l|}
\hline Variable & N & Mean & S.D. & Df & r-cal & r-tab & Remark \\
\hline Religious Affiliation & 300 & 10.98 & 1.62 & & & & \\
\cline { 1 - 4 } Youth Vulnerability to suicide & 300 & 1.17 & .374 & 298 & $54.090^{*}$ & 1.980 & Sig. \\
\hline
\end{tabular}


From the table 3 above, it was revealed that $r$-cal is greater than r-tab (r-cal $54.090>$ r-tab 1.980). This means that the null hypothesis was rejected, meaning that religious affiliation can effectively influence youth vulnerability to suicide.

\section{Research hypothesis 3}

There is no significant relationship between educational attainment and youth vulnerability to suicide.

Table-4: Pearson Correlation of Educational Attainment and Youth Vulnerability to Suicide

\begin{tabular}{|l|l|l|l|l|l|l|l|}
\hline Variable & N & Mean & S.D. & Df & r-cal & r-tab & Remark \\
\hline Educational Attainment & 300 & 18.067 & 8.090 & & & & \\
\cline { 1 - 5 } Youth Vulnerability to Suicide & 300 & 8.901 & 2.710 & 298 & $69.017^{*}$ & 1.980 & Sig. \\
\hline \multicolumn{7}{|c|}{ P < 0.05}
\end{tabular}

Table 4 above shows that educational attainment recorded mean score of 18.067 and standard deviation of 8.090 with youth vulnerability to suicide obtained a mean score of 8.901 and standard deviation of 2.710 ( The r-cal, $69.017<$ 0.05). Therefore, the null hypothesis is rejected, which implies that there is a significant relationship between educational attainment and youth vulnerability to suicide.

\section{DISCUSSION}

The result of this study showed that there is a significant relationship between gender and youth vulnerability to suicide. This implies that gender is a function of youth vulnerability to suicide. The finding is against that of Mba (2010) who noted that gender had no significant influence on the prevalence of suicidal behaviours among university undergraduates in South- Eastern states of Nigeria. According to him, gender differences in youth does not indicate that it is a male problem because young females continue to attempt suicide more often than young males but die less often because females tend to use less violent or fatal means especially overdosing while males prefer the usage of poison and dangerous weapons that kill quickly. This might be a reflection of male's roles, responsibilities and status in the African setting. Failure to carry out such roles and responsibilities can jeopardize status as the head which may likely lead him to commit suicide to safe his face. The reason adduced for male committing suicide more than female could be attributed to egoism which makes male not to share feelings with anybody even with their loved ones. Another reason could be the erroneous believe that death is better or preferred to ignominy.

This finding supports the observations of Powell (2013) who stressed that the number of male that committed suicide between 2001 and 2011 was far greater than that of female in the same period. Falana et al. (2017) also found that there is a gender disparity to people vulnerability to suicide. It was posited by Connor and Nock (2017) that suicide is more common among young people, male are more likely to commit suicide than female folk. This is evident in that, men tend to use more violet method such as shooting, stabbing, hanging, or jumping into seas/lagoon whereas women use less violent method such as drug overdose and taking of poisonous substances. However, they stressed that the aftermath effects of suicide by the mother of children are greater than when fathers commit suicide. Consequently, the study is in contrast with that of Adewuya and Oladapo (2019) who posited that female adolescents were more likely to engage in suicidal behaviours than their male counterparts. Suicidal behavior and attempt may commonly occur among female youth as a result of disappointments from opposite genders believed to be boyfriends or finances. Lack of shock absorber by some female youth to face life frustrations and forge ahead in life may lead them to commit suicide.

The result of analysis of this study further showed that there is a significant relationship between religious affiliations and youth vulnerability to suicide. The implication of this is that religious affiliation/attachment of individuals to a particular religious sect/organization can either make or mar individuals committing suicide. This is also tantamount to ones commitment to the doctrines of such religious sect. This is in consonance to the work of Falana et al. (2017) that posited that adherence to religious doctrines prevents people from committing suicide and can also promotes one committing suicide like the case of Abu Bakr al-Baghdadi, the former ISIL leader who detonated a suicide vest that killed him and his three children when the USA Army were after. And a good number of people have committed suicide through self-bombing Boko-Haram insurgency in Nigeria. Fasogbon, Agberotomi Olaseni and Oladele (2019) also found that high degree of religiosity was a protective factor against suicidal tendencies. It was established by the researchers that individuals with high religious belief reported to have unfavourable attitude towards suicide.

It was revealed from the study that there is a significant relationship between educational attainment and youth vulnerability to suicide. The 
study is related to that of Abel and Kruger (2005) who found that low educational attainment is associated with a higher risk of suicide as against high educational attainment which is associated with a better overall health and a lower mortality especially through suicide. In line with the findings of Abel \& Kruger (2005), Philips and Hempstead (2017) also found that educational attainment would reduce the vulnerability to committing suicide. It was further stated that people with higher educational attainment are less likely to commit suicide than the individuals who are not educated or highly educated. The duo emphasized that $1 \%$ increase in school completion would reduce suicide by $0.19 \%$, which indicates that more educated individuals are less likely to commit suicide due to higher level of satisfaction in life. The reason could be that the highly educated individuals are likely to face less financial/economic pressure as they do earn higher income and have the ability to meet the basic needs of life. On like those with less educational attainment who may less likely be able to meet the three basic needs of life-food, clothing and shelter (Abel \& Kruger, 2005; Philips \& Hempstead, 2017). However, abject poverty resulted from low or lack of education is one of the factors that facilitate vulnerability of youth to suicide.

\section{CONCLUSION}

Based on the findings of the study, it was concluded that gender, religious affiliation and educational attainment are highly related to youth vulnerability to suicide in Ekiti state. Therefore, the three socio-cultural views considered in this study cannot be over-emphasized as they were highly related to youth vulnerability to suicide in Ekiti state, Nigeria.

\section{RECOMMENDATIONS}

Based on the findings, it was recommended that:

- Parents should provide essential needs and equal opportunities for their children without preferential treatment or gender discrepancy.

- Religious leaders should preach commitment to God and encourage the followers to be vast in the right doctrinal teaching so that they (the followers) cannot be cajoled or fooled around by false preachers that are against human existence.

- Parents should give adequate moral and spiritual education to children/wards in order to provide better opportunities for them to make the ends meet and get rid of poverty and other economic/financial pressure that heighten vulnerability to suicide among the youths.

- Government should provide functional education through provision of necessary infrastructural facilities that could make learning more interesting and appealing to the youth. This could relief them from stress and life frustration which could lead to suicide.

- Government should provide job opportunities to the youth who are almost half of the nation's population. This could go a long way to distance them from drug abuse, cultism, anxiety, depression and life frustration which could eventually lead them to commit suicide.

- Government should intensify efforts on making moral and religious education compulsory at all levels of education. This could assist majority of the youth that have no sound religious background to gain moral and spiritual values in schools in order to promote rational thinking among them.

\section{REFERENCES}

- Abel, E. L., \& Kruger, M. (2005). Educational attainment and suicide rates in the United States of America. Psychological Report; 97(1), 25-28.

- Adewuya, A.O., \& Oladapo, E. O. (2019). Prevalence and associated factors for suicidal behaviours (ideation, planning and attempt) among high school adolescents in Lagos state, Nigeria. European Child and Adolescent Psychiatry. Retrieved from https://dol.org/10s00787-019. 01462-x on April 10, 2020.

- Animasahun, R. A., \& Animasahun, V. O. (2016). Psychological predictors of suicide mission among Nigerian youths. African Journal for the Psychological Study of Social Issues, 19(1), 79-102.

- Bertoloto, J. M., \& Fleichman, A. (2002). A global perspective in the epidemiology of suicide. Sociologist, 7, 1-8.

- Cannor, R. C., \& Nock, M. K. (2017). The psychological of suicidal behavior. The Lancet Pschiatry, 15(423), 1-14. https://www.researchgate.net/publication/26445 9723.

- Daily Times. (2018). The growing rate of suicides in Nigeria and common causes.2018 June14, Daily Times.

- Eneh, O.C. (2017). Attitudes of HPE students in Nigerian universities towards suicide. Unpublished Ph.D. thesis, Faculty of Education, Enugu State University of Technology (ESUT), Enugu.

- $\quad$ Eze, J. E., Chukwuorji, J. C., Ettu, P., Zacchaeus, E. A., Lorfa, S. K., \& Nwonyi, S. I. (2019). Bulling and suicide ideation: Test buffering hypothesis of social support sub-Saharan African sample. Journal of Child and Adolescent Trauma. https://doi.org/101007/s4o653-019-00294-w

- Falana, B. A., Onijigin, E. O., \& Alao, D. D. (2017). Prevalence of suicide attempts and counseling intervention strategies for victims of suicide. In J. A. Adegun, J. B. Babalola, \& I. A. Ajayi (Eds.), Dynamics of Education. 108-122. Ado-Ekiti: EKSU Press. 
- $\quad$ Fasogbon, M. A., Agberotimi, S. F., Olaseni, A. O., \& Oladele, O. T. (2019). Impact of religiosity and life orientation on attitude of youths towards suicide in Lagos, Nigeria: A religious-community based study. Covenant International Journal of Psychology, $4(1)$. http://www.journalsconvenantuniversity.edu.ng. Retrieved 24/4/2020.

- Kim, J. L., Kim, J. M., Choi, Y., Lee, T., \& Park, E. (2016).Effects of socio-economic status on the linkage between suicidal ideation and suicidal attempts. Suicide and Life-Threatening Behaviour, 46(5),

588-596. https://doi.org/10.1111/sltb.12242.

- Mba, S. A. (2010). Prevalence and prevention of suicidal behaviours among undergraduates of universities in south-eastern states of Nigeria: 1999-2008. An unpublished Ph. D thesis, Department of Health \& Physical Education, University of Nigeria, Nsukka.

- National Injury Mortality Surveillance System (NIMSS). (2007). A profile of fatal Injuries in South Africa (6 $6^{\text {th }}$ Annual Report) Retrieved from https://www.sahealthinfro.org/violence/national 2007.pdf.

- $\quad$ Nduka-Ozo, S. N. (2016). Counselling techniques as variable tools for attitudinal change of Nigerian youths. Journal of Research on Humanities and Social Sciences, 6(24), 1-6.

- Nnorom, K. (2019). Social anomie and suicide phenomenon in Nigeria: Lending credence to the voiceless phenomenon. RAIS Journal of Social Sciences, 1(3), 94-103.

- $\quad$ Nyundo, A., Manu, A., Regan, M., Ismail, A., Chukwu, A., Dessie, Y., Njau, T, Kaaya, S. F. \& Fawzi, B. (2020). Factors associated with depressive symptoms and suicidal ideation and behaviour amongst sub-Saharan African adolescents aged 1019years: Cross-sectional study. Tropical Medicine and International Health, 25(1), 54-69.

- Offiah, S. A. U., \& Obiorah, C. C. (2014). Pattern of suicide in Nigeria: The Niger-Delta experience. Journal of Medical Investigations and Practice, 9(1); 8-11.

- $\quad$ Oginyi, R. C., Mbam, O. S., Sampson, N., Chukwudi, E. J. \& Nwoba, M. O. E. (2018). Personality factors, academic stress and socio-economic status as factors in suicide ideation among undergraduates of Ebonyi State University. Asian Social Science, 14(9); 25-36.

- Okoedion, E . G., \& Okolie, U. C. (2019). Youth suicidal behaviour: An evaluation of risk factors in Edo State, Nigeria. International Scientific Journal, 125, 51-71.

- $\quad$ Philips, J. A., \& Hempstead, K. (2017). Differences in US suicide rate: Educational attainment (20002014). http://www.researchgate.net>publication.
- Powell, J. (2013). Suicide is a gender issue that can no longer be ignored. The Guardian, Wednesday, 23rd January, 2013.

- Uchendu, O. J., Ijomone, E. A., \& Nwachokor, N. F. (2019). Suicide in Warri, Delta State, Nigeria: An autopsy study. Annals of Tropical Pathology, 10(1), 16-19. http://www.atpjournal.org.>article. Retrieved on 24/4/2020.

- World Health Organisation (WHO). (2017). Diseases and injury country mortality estimates, 2000-2015 (Data files). Retrieved April 10, 2020.

- World Health Organisation (WHO). (2001). The world health report: Mental Health- New Understanding, New Hope. Geneva. 37

- World Health Organisation (WHO). (2008). Suicide prevention (SUPRE). Retrieved from http://www.who.int/mental_health/prevention/s uicide/suicide prevention/en/index.htm/

- World Health Organisation (WHO). (2009). Financial crisis and global health: Report of a highlevel consultation. Geneva: World Health Organisation.

- World Health Organisation (WHO). (2012). Public health action for the prevention of suicide. A framework. Geneva: WHO.

- World Health Organisation (WHO). (2013). Suicide data, Retrieved from https//www.who.ht>suicideprevention on April 10,2020

- World Health Organisation (WHO). (2013). Suicide Prevention (SUPRE). Retrieved from http://www.who.int/mentalheaith/prevention/su icide/suicideprevent/en/

- World Health Organisation (WHO). (2013). Suicide rate estimate, age-standardised-Estimates by country. $\quad$ Retrieved from https://www.apps.int>gho>data>view.

- World Health Organisation (WHO). (2018). Global health observation data on suicide mortality rate (per 100,000 population). http://www.who.int/glo/mental.health/suicide.ra te_crude/enl. Retrieved on 08/01/2020.

- World Health Organisation (WHO). (2018). Vanguard, https://www.vanguardngr.com/2018/09/800000 -people-commit-suicide-annually-who/

- World Health Organisation (WHO). (2019). Suicide in the world: Global health estimates. World Health Organisation, Geneva.

- World Health Organisation WHO. (2018). Depression and other common mental disorders. http://www.who.int/mental_healthmanagement/ depression/prevalence_global_health_estimates/e n/ Retrieved on September, 11, 2018. 